\title{
Laminated Composite Based on Polyester Geotextile Fibers and Polyurethane Resin for Coating Wood Structures
}

\author{
Yuri Andrey Olivato Assagra*, Ruy Alberto Pisani Altafim ${ }^{\text {b }}$,José Francisco Resende da Silvac, \\ Heitor Cury Basso ${ }^{\mathrm{a}}$, Francisco Antonio Rocco Lahr ${ }^{\mathrm{d}}$, Ruy Alberto Corrêa Altafim ${ }^{\mathrm{a}}$ \\ ${ }^{a}$ Department of Electrical Engineering, University of São Paulo - USP, Av. Trabalhador São Carlense, \\ 400, Centro, CEP 13566-590, São Carlos, SP, Brazil \\ ${ }^{\mathrm{b}}$ Computer Systems Department, Center of Informatics, Federal University of Paraíba - UFPB, \\ João Pessoa, PB, Brazil \\ ${ }^{\mathrm{c}}$ Elektro Eletricidade Serviços S.A., Rua Ary Antenor Souza, 1, CEP 13053-024, Campinas, SP, Brazil \\ ${ }^{\mathrm{d} D e p a r t m e n t ~ o f ~ S t r u c t u r a l ~ E n g i n e e r i n g, ~ U n i v e r s i t y ~ o f ~ S a ̃ o ~ P a u l o ~-~ U S P, ~ A v . ~ T r a b a l h a d o r ~ S a ̃ o ~ C a r l e n s e, ~}$ \\ 400, Centro, CEP 13566-590, São Carlos, SP, Brazil
}

Received: July 16, 2011; Revised: April 17, 2013

\begin{abstract}
New environmental laws have restricted the use of hardwood trees in overhead power lines structures, such as, poles and cross-arms, leading companies to seek alternative materials. Reforested wood coated with polymeric resin has been proposed as an environmental friendly solution, with improved electrical properties and protection against external agents, e.g. moisture, ultraviolet radiation and fungi. However, the single thin layer of resin, normally applied on such structures reveal to be inefficient, due to be easily damage during handling. In this paper, we present a composite coating, based on geotextile fibers and polyurethane resin that is suitable for wooden structures. Results obtained from two different tree species (from managed and reforested areas) coated with the composite reveal that the additional layer not only provided a stronger adhesion between wood and ccoating layer but also a further improvement in the electrical properties and better protection against abrasion and moisture.
\end{abstract}

Keywords: polyurethane resin, geotextile fibers, coating layer, wooden structural elements

\section{Introduction}

Wood is a versatile material that makes it suitable for a large number of applications that vary from structural elements on constructions sites to raw material for cellulose and paper manufacture. Not to mention that it also has a strong ecological appeal, if proper management and reforestation are employed in plantation zones. However, what makes wood a particularly special material is its low weight and high mechanical resistance ratio in addition to its intrinsic natural properties as thermal and electrical resistance. These properties combined are the desired characteristics for structural elements employed in transmission and distribution power lines such as, poles and cross-arms, responsible for supporting cables, insulators and electrical equipment.

Electrical insulation is a wood particularly important characteristic for insulation protection of power lines, where elements are exposed to over-voltages and lightning discharges ${ }^{1}$. In addition to these characteristics is the long life of the material, common to most hardwoods.

In recent years, new environmental laws have restricted the logging of native hardwoods, especially those species used in cross-arm production, such as Hymenaea courbaril L., Astronium urundeuva and Tabebuia chrysotricha ${ }^{2}$. This restriction has led to a decline in the availability of this material, leading to an increase in cross-arm costs.

*e-mail: yuriolivato@gmail.com
Several solutions have been adopted by different countries in order to reduce costs e.g. in Norway and United States, cross-arms are being produced from laminated wood pieces ${ }^{3,4}$ and in Brazil companies have opted to replace native woods with reforestation timbers, such as eucalyptus. Although reforestation wood presents some particular disadvantages, such as reduced mechanical resistance, lower electrical insulation and faster decay from weather exposure ${ }^{5}$. This last is crucial since most structures employed in distribution power lines are exposed to moisture, ultraviolet radiation, fungi and insects.

In order to avoid the effects of moisture and other environmental agents, some companies have opted to replace wood by concrete and recycled polymers. However, these materials have their own problems, such as, the production of concrete is not regulated according to environmental laws and concrete cross-arms are heavier, which increases transportation costs not to mention that they are more difficult to handle. Polymers on the other hand can be even more expensive than wood, especially when additives are mixed to provide protection against ultra-violet radiation and avoid degradation 6 .

Another solution that has proved popular with electricity companies in Brazil, better described by Altafim et al. ${ }^{7}$, was the coating of reforestation wood cross-arms with a thin layer of polyurethane resin. This not only promoted the 
necessary enhancement in the mechanical and electrical properties, but also created a protective layer against external agents. Nevertheless, companies that have opted for this solution has observed that the coating polymeric layer are easily damaged during transportation and handling, leaving parts of the wooden structure exposed.

In this paper, we describe the usage of a composite made of geotextile fibers and polyurethane resin to reinforce wooden structures against abrasion during handling. Laboratory tests performed on samples from two different wood species coated with the proposed composite indicate that not only the adhesion between wood and coating was improved, but also the water impermeability and electrical properties.

\section{Experimental Details}

\subsection{Sample preparation}

The alternative coating composite consists in a mixture of a bi-component resin and a non-woven polyester geotextile fiber $\left(200 \mathrm{~g} / \mathrm{m}^{2}\right.$ trade name GF10/200). The resin (trade name RP1315A) is composed in part by a polyol derived from castor oil and part by an aromatic pre-polymer that comes from diphenylmethane diisocyanate. Both resin and geotextile were purchased from Brazilian companies: Imperveg and Ober Geossinteticos, respectively.

In order to produce the composite the polyol and the pre-polymer were mixed in a $1: 1.5$ ratio in a vacuum mixer for three minutes to reduce gas bubbles, afterwards the resin was manually poured out and spread over the geotextile, which was wrapped in the wood samples.

To test the composite coverage, pieces of wood were previously cut from Dinizia excelsa Ducke and Pinus taeda (loblolly pine) trees, sourced from managed and reforestation areas, respectively. The samples initially covered with the geotextile fiber and then coated with resin, formed a threelayer system, as illustrated in Figure 1. The initial fluid state of the resin and the high porosity of the geotextile fiber allowed the resin to penetrate into the fabric and reach the surface of the wood, bonding all the components together after curing. It is important to emphasize that the coating layer increases the sample thickness in approximate $2 \mathrm{~mm}$.

Later, coated and uncoated samples were mechanically and electrically tested according to standard process normally required for electrical structures. Abrasion test was performed on samples coated only with resin and with the geotextile composite, for a comparison. And water absorption and adhesion tests were further implemented to analyze the effect of moisture on the composite and to verify the adherence strength of the coating.

\subsection{Flexural mechanical characterization}

Flexural properties, such as, elastic and rupture moduli, are regularly tested on electrical structures, such as crossarms since they are expected to support the weight of equipment and cables. Therefore to verify the influences of the geotextile composite on these wooden structures, the flexural properties were determined in accordance with ABNT NBR 7190 - Appendix $B^{8}$.
The flexural properties (elastic and rupture moduli) were measured using a three-point loading system applied to a wood supported beam, as represented in Figure 2. An Amsler universal testing machine was employed as the central force and the sample displacement was measured with a Mitutoyo Ltda dial indicator. The measurements were performed on fourteen prism-shaped samples ( $30 \mathrm{~mm}$ width, $38 \mathrm{~mm}$ height and $400 \mathrm{~mm}$ long) cut from the same tree (for each specie) to prevent large variations in their structural fibers.

From the displacement measurements and the maximum supporting load, the Rupture modulus - $\left(S_{R}\right)$ and the Elastic modulus, $\left(E_{f}\right)$ were determined. $S_{R}$ was calculated as if the wood was an elastic material using Equation $1^{8}$,

$S_{R}=\frac{3 P_{\max } L}{2 b h^{2}}$

where $P_{\max }$ is the maximum load applied on the sample at rupture, and $b, h$ are the sample dimensions width and height, respectively and $\mathrm{L}$ is the support span.

The $E_{\rho}$ given by Equation $2^{8}$ is determined from the linear region on the strain-stress diagram, with $\Delta$ being the strain variation at $\left(\operatorname{Strain}_{2500 \mathrm{~N}}-\right.$ Strain $\left._{500 \mathrm{~N}}\right)$ and $P$ the stress variation in the aforementioned stress interval.

$E_{f}=\frac{P L^{3}}{4 b h^{3} \Delta}$

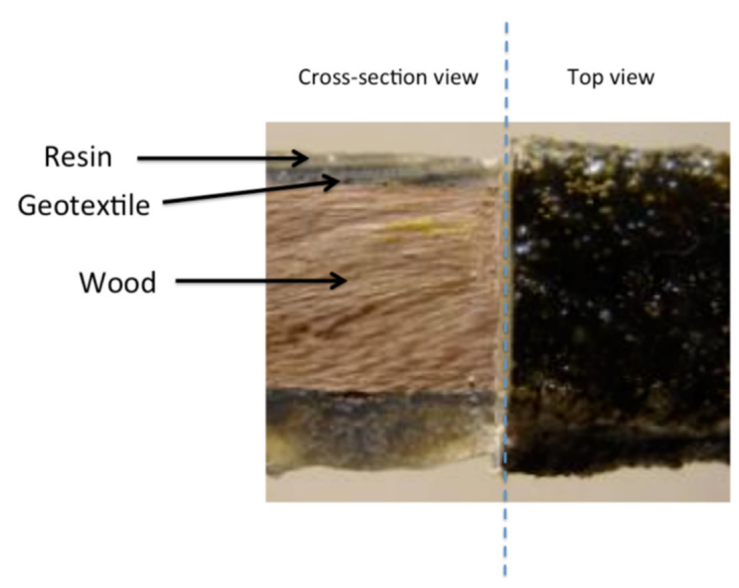

Figure 1. Cross-section view with sequence of layers on samples coated with geotextile fibers and polyurethane composite resin.

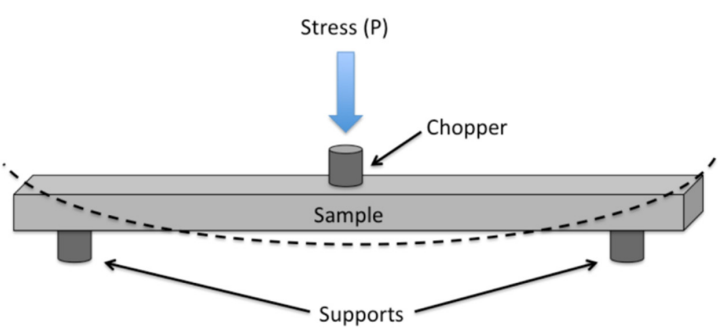

Figure 2. Schematic diagram of the static bending test to characterize the reduced scale cross-arm. 


\subsection{Pin-on-Disc Wear Test}

In order to verify damages caused by abrasions on the geotextile with resin coating layer, a pin-on-disc wear test was performed according to ASTM G99 ${ }^{9}$. The test consist in promote a friction between the sample surface and a rigid pin. For this, samples designed with circular shapes were clamped to a support that can rotates up to a certain speed while a fix pin, scratches the sample surface. The pin is supported by a mechanical arm with several predefined fixing places and is designed to support additional superimposed loads. The loads are added to further test the surface resistance limits. Details of the setup are schematic represented in Figure 3a.

Preliminary test was performed on circular samples with approximate $102 \mathrm{~mm}$ in diameter and $12 \mathrm{~mm}$ thick in order to identify the setup parameters, such as, rotation speed, superimposed load and experimental time. From this, the following parameters were obtained: $100 \mathrm{rpm}, 1000 \mathrm{~g}$ and $20 \mathrm{~min}$, respectively. A stainless steel pin was employed, due to its higher rigidity if comparable to the resin or the geotextile composite. After the test was performed an abrasion track, on the sample surfaces, could be observed. The track deepness was analyzed with a linear variable differential transformer (LVDT) precise in microns.

Nevertheless, due to the coating process it is expected some thickness heterogeneity on the samples surfaces, therefore measurements of track deepness were performed at three different places: outside the track (named region a), on the track (region T) and inside the track (region b), as indicated in Figure 3b. For each area, 28 measurements were taken for an averaged value.

\subsection{Volume and Surface Resistivity}

The proposed coating layer i.e. geotextile fabric and resin is expect to be employed on electrical structures which are subjected to intense electrical fields. Therefore, analyze its volumetric and surface resistivity is crucial to prevent damages on the coated structures, once these parameters are relevant in cases of resistivity reduction and current leakage ${ }^{10}$. Here, the volumetric and surface resistivity, of coated samples were verified according to standard measurements for insulating materials (ASTM D25711), which were conducted with a standard resistivity cell model 16008B, designed as illustrated in Figure 4, and a standard resistivity meter model 4339B, both from Agilent.

According to the ASTM D257'11, the volumetric and surface resistivity measure must be performed applying an $80 \mathrm{~N}$ load to circular shaped samples superimposed to ensure contact between the cell electrodes and sample. Wooden disks of $100 \mathrm{~mm}$ in diameter and $10 \mathrm{~mm}$ thick from Dinizia excelsa Ducke and Pinus taeda (loblolly pine) trees were cut and coated as previously described, resulting in samples with final dimensions of $102 \mathrm{~mm}$ and $12 \mathrm{~mm}$, respectively. A $500 \mathrm{~V}$ DC voltage was applied for $60 \mathrm{~s}$ to perform the measurements.

\subsection{Dielectric breakdown voltage}

Electrical discharges are regularly occurring in distribution power lines systems, therefore the equipment and structures should support this overvoltage conditions.

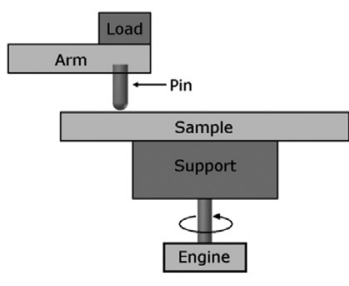

(a)

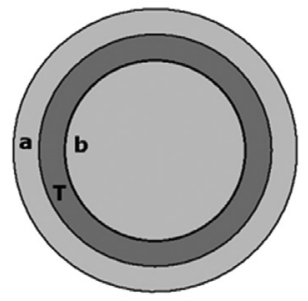

(b)
Figure 3. a) Schematic representation of the Pin-on-Disc Wear Test and b) areas measured with LVDT after Pin-on-Disc Wear Test.

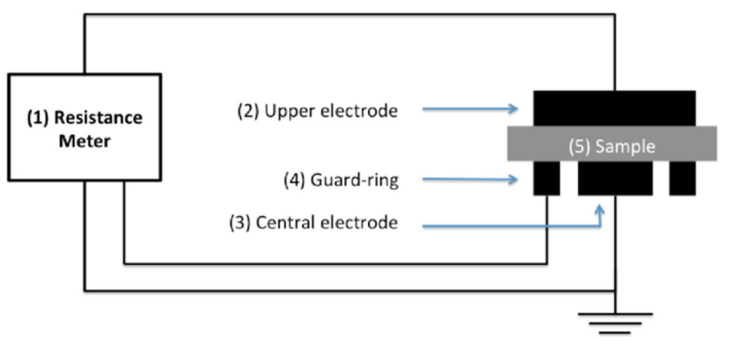

Figure 4. Schematic diagram of the experimental setup to measure volume and surface resistivity.

As explained by Darveniza et al. ${ }^{1}$, the wood in these circumstances can act as an additional insulation, increasing the dielectric strength of the structure and thus reducing the energy associated to electric arcs. Once, the geotextile composite is applied to these structures, it is important to determine its dielectric breakdown voltage.

For this, measurements were carry according to ASTM D $149^{12}$, which describes three methods for determine the dielectric strength. The most common, that was also employed here, is the Short-Time Test, which consists in apply an increasing voltage through the sample until it reaches electrical breakdown. The samples were enclosed inside a containing mineral oil chamber to avoid external breakdown, which normally occurs in the air around the sample due to its lower dielectric strength. Circular wooden samples of $102 \mathrm{~mm}$ in diameter and $12 \mathrm{~mm}$ thick were submerged in the oil chamber and placed between two hemispherical electrodes, $56 \mathrm{~mm}$ and $68 \mathrm{~mm}$ in diameter. A voltage with a ramp rate of $500 \mathrm{~V} / \mathrm{s}$ was directly applied to the electrodes for $20 \mathrm{~s}$ through a HAEFELY-TRENCH kit consisting of a TEO 100/10 transformer and a DMI 551 control table.

\subsection{Permittivity and dielectric loss (tan $\delta$ )}

Permittivity and $\tan \delta$ together with structural geometrical parameters are normally employed on the description of the electrical model accepted on coordination insulation studies ${ }^{1}$ used during computer simulations. On this model the wood structure is represented in serial with a porcelain insulator, as in a circuit with a capacitor in parallel with a resistor. Therefore, determine those electrical properties, is complementary to improve the model. And in order to measure the permittivity and the $\tan \delta$ of uncoated and coated samples, circular wooden disks were cut with 
approximately $22 \mathrm{~mm}$ in diameter. The disks were separated into two sets: samples from Dinizia excelsa Ducke and Pinus taeda, which were 10 and $7 \mathrm{~mm}$ thick, respectively. Both sets were coated with a $4 \mathrm{~mm}$ geotextile-resin layer and painted with a conductive paint to ensure electrical contact. Later the measurements were performed in a dielectric material test fixture model 16451B from Agilent connected to a precision LCR meter, model 4284A, also from Agilent, as described in ASTM D150 $0^{13}$.

\subsection{Absorption analysis}

Temperature and high humidity exposures tests according to the technical standard IEC $60068^{14}$ have been performed on wooden samples coated with the polyurethane resin employed here and as reported no negative influence could be observed ${ }^{15}$. The influence of weather conditions on the mechanical properties of the polyurethane resin was also investigated in an artificial environment and only small changes was observed, mainly concerning the resistance to traction and the elastic modulus, which in both cases increased, meaning that the samples became more resistant to traction after being exposed for a certain period and less flexible ${ }^{16}$ i.e. more brittle.

Nevertheless, in order to verify if the proposed composite could also protect the wood against humidity, which is the major concern on electrical structures, water absorption tests were performed on coated and uncoated samples for comparison.

The process to evaluate absorption employed here was relatively simple, consisting in measuring the weight of the sample before and after a $24 \mathrm{~h}$ period of immersion. For this study, the samples were initially dried in an oven heated at $100{ }^{\circ} \mathrm{C}$ and weighed. Later the samples were submersed in a polyethylene box containing deionized water at $25^{\circ} \mathrm{C}$ as recommended by ASTM D570 ${ }^{17}$. Sample holders were used to avoid sample flotation. After immersion, the samples were surface-dried with a clean cloth and again weighed. From the difference between weights, it was possible to determine how much water the samples absorbed.

\subsection{Adhesion}

One of the major concerns of the proposed coating layer, besides addition to protection against external agents and improvement of electrical properties and abrasion, was to provide an efficient covering of the wood structures that also prevents damage caused during handling and transportation. For this, an adhesion test between wood and coating was performed by sticking together two pieces of wood with castor oil resin or with the castor oil and geotextile fiber. Wood pieces of $30 \mathrm{~mm}$ $\times 38 \mathrm{~mm} \times 50 \mathrm{~mm}$ were used and bonded together at the $30 \mathrm{~mm} \times 38 \mathrm{~mm}$ surfaces. After the resin was cured (period of $24 \mathrm{~h}$ ), the samples were half placed in a fixed sample holder leaving the bonding piece complete free, as schematically represented in Figure 5. A hydraulic press was than employed to apply an increasing force on the free side of the sample, forcing it to shear. The applied force was recorded until it reached its maximum value at the detach moment.

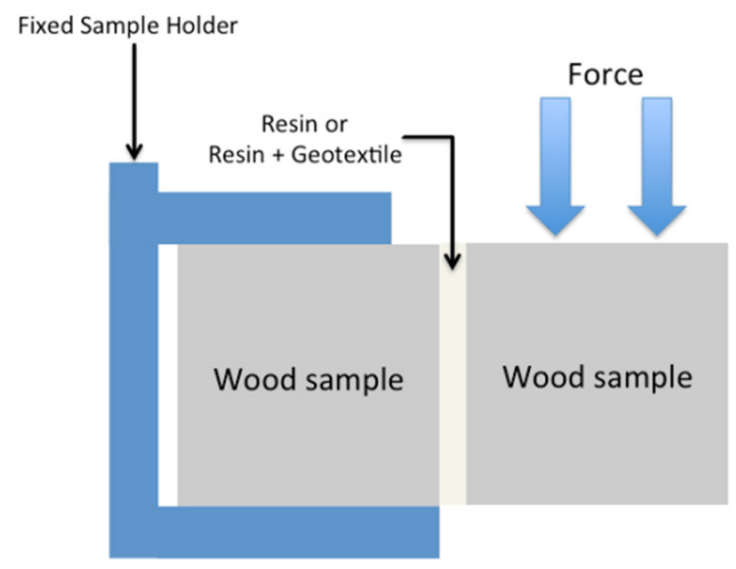

Figure 5. Schematic diagram of the experimental setup to measure the adhesion between the wood and the coating layer.

\section{Results and Discussion}

The maximum tensile strength at rupture and the elastic modulus of uncoated and coated samples, cut from the same tree for each wood species, are presented in Figure 6 and 7. In Table 1 the values are presented with the acronym RG to reference samples coated with geotextile fiber and resin and $\mathrm{R}$ to reference samples coated only with resin.

As one can see from these results, the coated samples presented a lower elastic modulus when compared to uncoated ones. This behavior can be explained considering the coated structure as a three-layer element (coating layer - wood - coating layer) as propose in Cho and $\mathrm{Kim}^{18}$ and US Forest Service Research Note ${ }^{19}$. Disregarding the coating sides and the shear modulus, the three-layer model for the overall elastic modulus, $E_{f}$, can be obtained from Equation 3.

$E_{f}=\frac{E_{1} I_{1}+E_{2} I_{2}+E_{3} I_{3}}{I_{1}+I_{2}+I_{3}}$

where, $E_{1}, E_{2}$ and $E_{3}$ correspond to the elastic modulus of each material layer and $I_{1}, I_{2}$ and $I_{3}$ are the respective second moments of inertia give by Equation $4^{18}$.

$$
\begin{aligned}
& I_{1}=w\left[\left(d_{2}-d\right)^{2} d_{1}+\left(d_{2}-d\right) d_{1}^{2}+d_{1}^{3}\right] \\
& I_{2}=w\left[\frac{d_{2}^{3}}{3}-\left(d_{2}^{2} d\right)+\left(d_{2} d^{2}\right)\right] \\
& I_{3}=w\left[d_{3}^{3}+\left(d_{3}^{2} d\right)+\left(d_{3} d^{2}\right)\right]
\end{aligned}
$$

where, $w$ is the sample width, $d_{1}, d_{2}$ and $d_{3}$ are the layer 1, 2 and 3 thickness, respectively, and $d$ is the distance from the neutral plane to the interface between layers 2 and 3, as shown in Figure 8. 


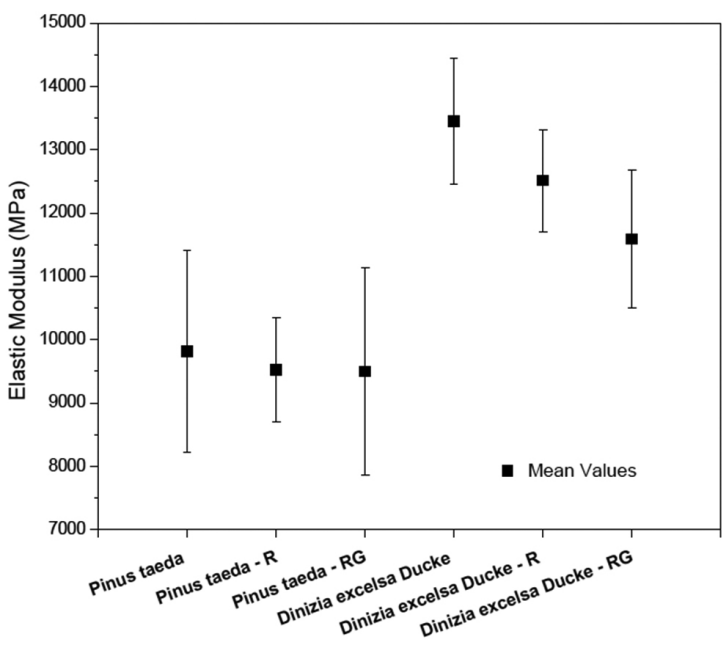

Figure 6. Elastic modulus from samples: in natural state, coated with resin $(\mathrm{R})$ and coated with resin and geotextile fiber (RG).

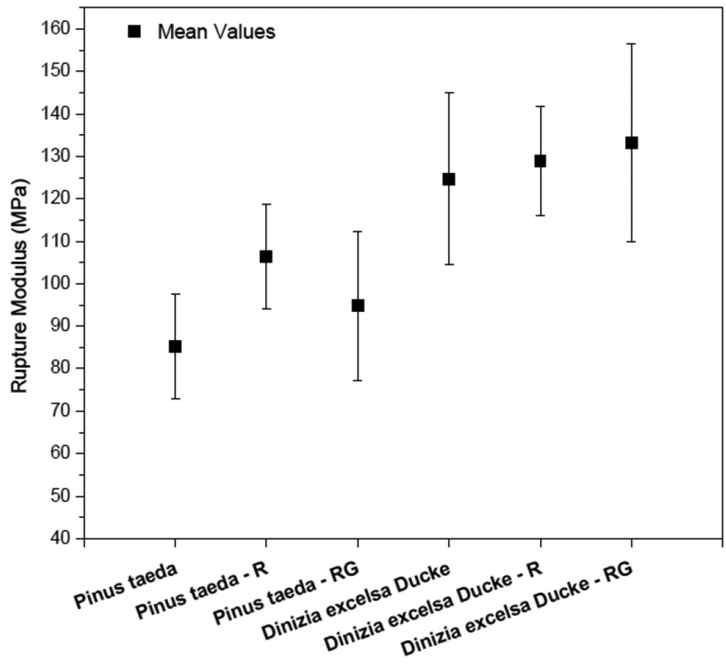

Figure 7. Rupture modulus from samples: in natural state, coated with resin $(R)$ and coated with resin and geotextile fiber $(R G)$.

Table 1. Modulus of elasticity and modulus of rupture of uncoated and coated samples cut from random wood pieces.

\begin{tabular}{lccc}
\hline \multicolumn{1}{c}{ Wood } & Coating & Ef(MPa) & SR (MPa) \\
\hline Pinus taeda & - & $9813 \pm 16 \%$ & $85 \pm 14 \%$ \\
Pinus taeda & R & $9516 \pm 9 \%$ & $106 \pm 12 \%$ \\
Pinus taeda & RG & $9491 \pm 17 \%$ & $95 \pm 18 \%$ \\
Dinizia excelsa Ducke & - & $13448 \pm 7 \%$ & $124 \pm 16 \%$ \\
Dinizia excelsa Ducke & R & $12511 \pm 6 \%$ & $129 \pm 10 \%$ \\
Dinizia excelsa Ducke & RG & $11587 \pm 9 \%$ & $133 \pm 17 \%$ \\
\hline
\end{tabular}

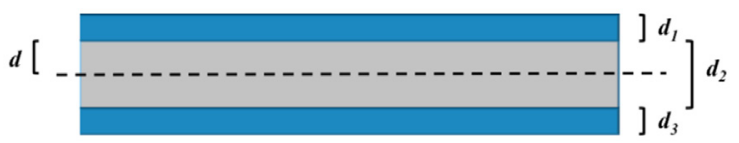

Figure 8. Shematic cross-section of the coated strucuture with respective thickness layers.
Assuming, that layers 1 and 3 are identical, Equation 3 can be rearranged, leading to Equation 5, which can be used to determine the elastic modulus of multi-layered elements.

$$
E_{f}=\frac{2 E_{1} I_{1}+E_{2} I_{2}}{2 I_{1}+I_{2}}
$$

Replacing the elastic moduli in Equation 5 by its correspondent values: $E_{1}=2.2 \mathrm{MPa}$ for the coating layer obtained from the flexural measurements and $E_{2}=9813 \mathrm{MPa}$ for Pinus taeda or $13448 \mathrm{MPa}$ for Dinizia excelsa Ducke (calculated values as in Table 1), multi-layer elastic moduli of $7256 \mathrm{MPa}$ and $9943 \mathrm{MPa}$, can be obtained for Pinus taeda and Dinizia excelsa Ducke, respectively. From this, one can observe that the elastic modulus of the multi-layer structure is reduced with the additional layer.

Besides the elastic modulus of the coating layer, the shear modulus of samples with geotextile and resin coating assumes great relevance, preventing the structure to reach the rupture in an early stage as presented by the higher rupture modulus $\left(S_{R}\right)$, also in Table 1 .

Nevertheless, high standard variations between measurements are observed even from samples from the same wood piece, meaning from a statistical analysis, that there were no significant improvements on the flexural mode when samples are coated only with resin or with the geotextile composite.

On the pin-on-disc wear test performed to verify damages during abrasion, a more significant result was obtained. As can be seen in Figure 9, samples coated only with polyurethane resin (Figure 9a) were hardly damaged, presenting areas in which the resin was complete removed. On the other hand, samples coated with geotextile and resin (Figure 9b) presented only a small track caused by the contact with the metallic pin.

Measurements from the track deepness were taken as previously describe and are presented in average values in Table 2. On the resin coated samples a track deepness of $0.176 \mathrm{~mm}$ was found while only $0.0208 \mathrm{~mm}$ was obtained on samples coated with geotextile and resin. This result strongly indicates that the presented coating provided a better protection for handling.

Table 3 shows the results from the electrical measurement of the dielectric strengths for uncoated and coated samples. The obtained values indicate that both coating layers, i.e. with resin or resin and geotextile fiber, improved the dielectric strength on both wood species. However, samples coated with geotextile and resin presented breakdown strength approximate three times higher than samples coated only with resin, which was around $1.2 \mathrm{kV} / \mathrm{mm}$ greater than natural samples.

The increase in dielectric strength of coated samples can be explained comparing the composite (wood coated with resin or geotextile and resin) to a first approximation of an electrical circuit composed by two capacitors connected in serial, where one of them represents the wood (permittivity and thickness) and the other the coating layer (permittivity and thickness). In this model, the electrical field is proportional distributed to the materials permittivity, therefore, the layer with the lower permittivity, in this case 


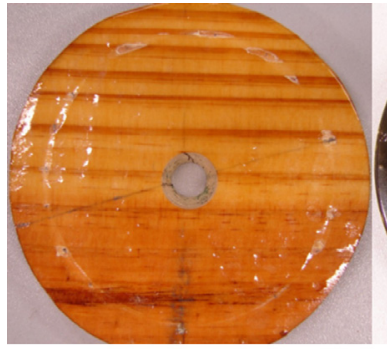

(a)

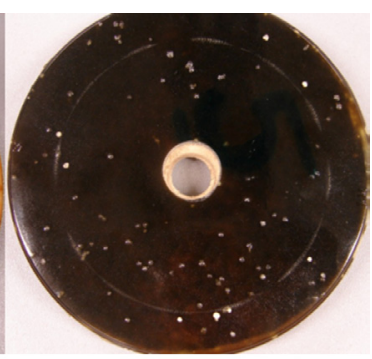

(b)
Figure 9. Images from the Pin-on-Disc Wear Test on samples coated with resin (a) and geotextile-resin (b).

Table 2. Results from the pin-on-disc wear test.

\begin{tabular}{ccc}
\hline Sample Coating & $\begin{array}{c}\text { Mean Thickness } \\
(\mathbf{m m})\end{array}$ & $\begin{array}{c}\text { Mean Track } \\
\text { Thickness }(\mathbf{m m})\end{array}$ \\
\hline $\mathrm{R}$ & 10.03 & 9.85 \\
$\mathrm{RG}$ & 18.95 & 18.93 \\
\hline
\end{tabular}

Table 3. Dielectric strength of uncoated and coated samples.

\begin{tabular}{lcc}
\hline \multicolumn{1}{c}{ Wood } & Coating & Dielectric Strength \\
\hline (kV/mm) & & \\
Pinus taeda & - & $2.2 \pm 14 \%$ \\
Pinus taeda & $\mathrm{R}$ & $3.4 \pm 8 \%$ \\
Pinus taeda & $\mathrm{RG}$ & $6.2 \pm 3 \%$ \\
Dinizia excelsa Ducke & - & $1.5 \pm 7 \%$ \\
Dinizia excelsa Ducke & $\mathrm{R}$ & $2.3 \pm 16 \%$ \\
Dinizia excelsa Ducke & $\mathrm{RG}$ & $5.9 \pm 5 \%$ \\
\hline
\end{tabular}

the coating layer, is submitted to a more intense electric field, thus reducing the electrical stress on the wood promoting an increase in the overall dielectric strength.

The lower permittivity and $\tan \delta$ (current leakage) of the wood-geotextile-resin composite are presented in Table 4. And it can also be explained by the same capacitors in serial model. However, one must consider that each capacitor has also a resistor in parallel associated to it (see Figure 10) and each capacitor in parallel with a resistor represents a different material in the composite. According to this model, the overall permittivity $(\varepsilon)$ can be calculated by the Expression $6^{20}$, where $\varepsilon_{i}$ is the material permittivity and $P_{i}$ the material volume ratio. Thus, replacing the measured permittivity into Equation 6 and its respective layer thickness it was possible to obtain theoretical permittivities values of $3.4 \pm 1.5 \%$ and $5.9 \pm 6 \%$ for Pinus taeda and Dinizia excelsa Ducke wood samples coated with geotextile composite. And these values are very much in agreement to those measured ones of $3.5 \pm 2.9 \%$ and $5.8 \pm 2.7 \%$, respectively.

$\frac{1}{\varepsilon}=\sum_{i=1}^{n} \frac{P_{i}}{\varepsilon_{i}}$

The resistor-capacitor model presented in Figure 10 can also be employed to explain the decrease in the $\tan \delta$ shown in Table 4. As the model has its capacitors in parallel with
Table 4. Permittivity and $\tan \delta$ of uncoated and coated samples.

\begin{tabular}{lccc}
\hline \multicolumn{1}{c}{ Wood } & Coating & Permittivity $(\varepsilon \mathbf{r})$ & $\tan \delta$ \\
\hline Geotextile and resin & - & $3.6 \pm 2.3 \%$ & 0,02 \\
Pinus taeda & - & $3.1 \pm 0.5 \%$ & 0.40 \\
Pinus taeda & RG & $3.5 \pm 2.9 \%$ & 0.07 \\
Dinizia excelsa Ducke & - & $10.2 \pm 4.7 \%$ & 0.58 \\
Dinizia excelsa Ducke & RG & $5.8 \pm 2.7 \%$ & 0.06 \\
\hline
\end{tabular}

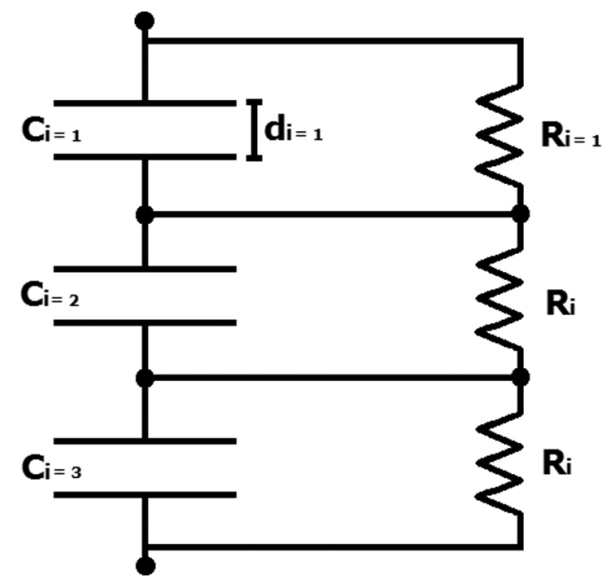

Figure 10. Schematic electrical circuit that represents the multilayer composite (wood-geotextile fiber-resin).

its resistors, and they are associated in series, the equivalent resistance is higher than on uncoated wood, and since the $\tan \delta$ is inversely associated with the material resistance it tends to be lower, as found during measurements. The increasing in the equivalent resistance of the composite material also explain the higher values of volumetric and superficial resistivity shown in Table 5, once they are directly associated to it.

Another property investigated in this study was the influence of moisture, which has a major impact on wood, such as, variation on the elastic modulus as described in Silva et al. ${ }^{21}$ and Gerhard ${ }^{22}$. Therefore measuring how much water the material can absorb is an important way to determine the behavior of the wood when exposed to high humidity environments. Here, the results from the water absorption test are presented in Table 6 for uncoated and coated samples from the two varieties of wood.

From the comparison, one can observe that after immersion, the mean percentage of absorbed water increases more than $60 \%$ on uncoated samples from Pinus taeda and more than $30 \%$ on uncoated samples from Dinizia excelsa Ducke. This difference between the two wood species is partially explained by the higher porosity of Pinus taeda structure compared to Dinizia excelsa Ducke (see SEM images in Figure 11). 
Table 5. Volumetric and superficial resistivity of uncoated and coated samples.

\begin{tabular}{lccc}
\hline \multicolumn{1}{c}{ Wood } & Coating & $\begin{array}{c}\text { Vol. Res. } \\
(\Omega \mathbf{c m})\end{array}$ & $\begin{array}{c}\text { Sup. Res. } \\
(\Omega)\end{array}$ \\
\hline Pinus taeda & - & $6.3 \mathrm{E}+10$ & $5.3 \mathrm{E}+11$ \\
Pinus taeda & $\mathrm{R}$ & $2.2 \mathrm{E}+14$ & $6.7 \mathrm{E}+14$ \\
Pinus taeda & $\mathrm{RG}$ & $2.1 \mathrm{E}+15$ & $3.1 \mathrm{E}+15$ \\
Dinizia excelsa Ducke & - & $2.4 \mathrm{E}+9$ & $1.4 \mathrm{E}+10$ \\
Dinizia excelsa Ducke & $\mathrm{R}$ & $1.3 \mathrm{E}+15$ & $1.4 \mathrm{E}+15$ \\
Dinizia excelsa Ducke & $\mathrm{RG}$ & $6.7 \mathrm{E}+14$ & $1.1 \mathrm{E}+16$ \\
\hline
\end{tabular}

Table 6. Percentage of water absorbed in uncoated and coated samples.

\begin{tabular}{lcc}
\hline \multicolumn{1}{c}{ Wood } & Coating & Mean Value (\%) \\
\hline Pinus taeda & - & $62.8 \pm 3$ \\
Pinus taeda & $\mathrm{R}$ & $4.0 \pm 14$ \\
Pinus taeda & $\mathrm{RG}$ & $0.7 \pm 13$ \\
Dinizia excelsa Ducke & - & $32.3 \pm 5$ \\
Dinizia excelsa Ducke & $\mathrm{R}$ & $3.8 \pm 3$ \\
Dinizia excelsa Ducke & $\mathrm{RG}$ & $0.6 \pm 17$ \\
\hline
\end{tabular}

a)

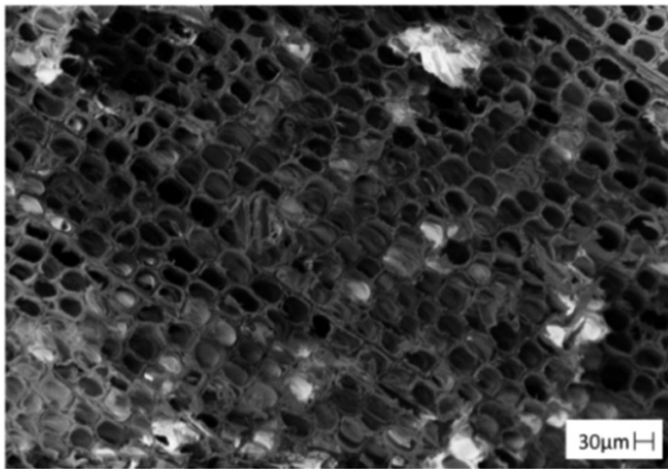

b)

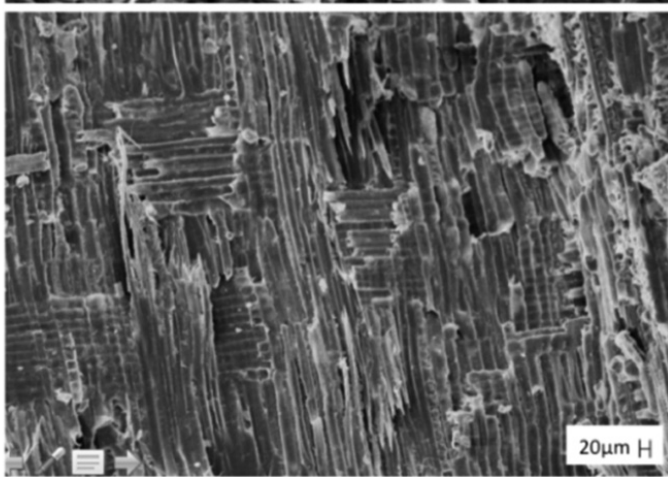

Figure 11. SEM images from a) Pinus taeda and b) Dinizia excelsa Ducke samples.

Nevertheless, a drastic reduction in the percentage of absorbed water is observed on both coated samples ( $\mathrm{R}$ and $\mathrm{RG})$. On samples coated only with resin a percentage of approximately $4 \%$ was found while for the geotextile coated samples the absorption was $0.6 \%$, indicating that the coating provides strong impermeability.
Table 7. Maximum force applied in the adhesion test on coated samples with resin and resin and geotextile.

\begin{tabular}{lcc}
\hline \multicolumn{1}{c}{ Wood } & Coating & $\begin{array}{c}\text { Detaching Force } \\
(\mathbf{N})\end{array}$ \\
\hline Pinus taeda & $\mathrm{R}$ & $6544 \pm 10 \%$ \\
Pinus taeda & $\mathrm{RG}$ & $7845 \pm 10 \%$ \\
Dinizia excelsa Ducke & $\mathrm{R}$ & $4305 \pm 20 \%$ \\
Dinizia excelsa Ducke & $\mathrm{RG}$ & $7420 \pm 14 \%$ \\
\hline
\end{tabular}

For the last, adherence test was performed as previously described to verify the bounding between the coating layers and wood piece. The maximum forces applied before the samples sheared are presented in Table 7 with regard to the bonding layer. As can be seen, the use of an extra geotextile layer has improved the bonding of both wood species, especially on the Dinizia excelsa Ducke samples. We believe that the geotextile layer reduces the tension between the bonding surfaces and the resin distributes the force through the fabric, thus enhancing the adhesion. Although the amount of resin used to fix the wood pieces together and the surface roughness are also parameters that could influence the adherence and needs to be more careful analyzed.

\section{Conclusion}

An alternative composite made of polyester geotextile fibers and castor-oil polyurethane resin for coating wood structures was presented. The coating layer was applied on two different wood species, Dinizia excelsa Ducke and Pinus taeda, from managed and reforested areas, respectively, for a comparison. Static bending tests were performed in accordance with ABNT NBR 7190 - Appendix B $^{8}$ to determine the rupture and elasticity moduli of coated samples. Results indicated that by coating the samples with softer layers reduces the elastic modulus and increases the rupture modulus, allowing the samples to withstand larger deformation before breaking. Electrical measurements of volume and surface resistivity of coated samples were also performed and revealed that these properties were substantially enhanced when compared to the uncoated samples, providing much better insulation. Measurements of the composite permittivity and $\tan \delta$ indicated good agreement with well accept models and were applied on the observed electrical behaviors explanation. Still regarding electrical measurements, a significant improvement was obtained on the dielectric breakdown strength of coated samples, which was enhanced by at least $1.2 \mathrm{kV} / \mathrm{mm}$ on samples coated with a single resin layer and by a factor of three on samples coated with resin and geotextile. On water absorption tests a dependence on the wood fiber structure was observed, although the extra coating layer proved to be very much efficient in reducing the percentage of absorbed water, from $62.8 \%$ to $0.7 \%$ in the case of Pinus taeda samples and from $32.3 \%$ to $0.6 \%$ on Dinizia excelsa Ducke samples. Another significant improvement promoted by the coating layer with resin and geotextile fiber was concerning the adherence between wood and coating. On the performed test, the bonding between two wood pieces was more 
efficient when resin and geotextile fiber were used as the adhesive element rather than when only resin was applied. Nevertheless, the aim of the proposed coating was to reduce damages caused during transportation and handling of the wood pieces, therefore a pin-on-disk test was performed and from the track deepness and appearance became clear that the samples coated only with resin suffer a much larger damage than samples coated with the geotextile and resin layer. To summarize, the proposed alternative coating proved to be very efficient in improving the mechanical and electrical properties of wood structured from managed and

\section{References}

1. Darveniza M, Limbourn GJ and Prentice SA. Line design and electrical properties of wood. IEEE Transactions on Power Apparatus and Systems. 1967; (11):1344-1356.

2. Associação Brasileira de Normas Técnicas-ABNT. NBR 8458: Wood crossheads for electric energy distribution networks. Rio de Janeiro: ABNT; 1984. 13 p.

3. Liebel SA and Mueller RE. Douglas fir crossarms: solid sawn vs. laminated comparison. In: Proceedings of the Transmission and Distribution Conference; 1994; Chicago. IEEE Press; 1994. p. 581-586. http://dx.doi.org/10.1109/ TDC.1994.328427

4. Asboll E. Laminated wood structures in Norwegian transmission lines. In: Proceedings of the International Conference on Overhead Line Design and Construction: Theory and Practice; 1988; London. IEEE Press; 1988. p. 36-39.

5. Trevisan H, Tieppo FMM, Carvalho AG and Lelis RCC. Evaluation of physical and mechanical properties of wood from five species as a function of deterioration in two environments. Revista Árvore. 2007; 31(1):93-101.

6. Andrady AL, Hamid SH, Hu X and Torikai A. Effects of increased solar ultraviolet radiation on materials. Journal of Photochemistry and Photobiology B: Biology. 1998; (46):96103. http://dx.doi.org/10.1016/S1011-1344(98)00188-2

7. Altafim RAC, Silva JPR, Gonzaga DP, Ribeiro C, Godoy J, Basso $\mathrm{HC}$ et al. Wood cross-arms coated with polyurethane resin-tests and numerical simulations. Materials Research. 2006; 9(1):7781. http://dx.doi.org/10.1590/S1516-14392006000100015

8. Associação Brasileira de Normas Técnicas-ABNT. NBR 7190: Design of wooden structures. Rio de Janeiro: ABNT; 1997. $107 \mathrm{p}$.

9. American Society for Testing and Materials - ASTM. G99: Standard Test Method for Wear Testing with Pin-on-Disk Apparatus. ASTM; 2010.

10. Ross PM. Burning of Wood Structures by Leakage Currents. Transactions of the American Institute of Electrical Engineers. 1947; 66(1):279-287. http://dx.doi.org/10.1109/TAIEE.1947.5059441

11. American Society for Testing and Materials - ASTM. D257: Standard Test Methods for DC Resistance or Conductance of Insulating Materials. ASTM; 2007. reforested areas and also in protecting the material against external agents, such as humidity.

\section{Acknowledgments}

Authors would like to thanks Prof. Dra. Elisabete Frollini and Prof. Dr. Luiz Carlos Casteletti for providing laboratory facilities. And many thanks to Sergio Aparecido Trevelin from the (LCC/EESC/USP) and Jaime Galindo (LaMEM/EESC/USP), for their assistance with the mechanical characterizations.
12. American Society for Testing and Materials - ASTM. D149: Standard Test Method for Dielectric Breakdown Voltage and Dielectric Strength of Solid Electrical Insulating Materials at Commercial Power Frequencies. ASTM; 2009.

13. American Society for Testing and Materials - ASTM. D150: Standard Test Methods for AC Loss Characteristics and Permittivity (Dielectric Constant) of Solid Electrical Insulation. ASTM; 2004.

14. Intenational Electrotechnical Commission - IEC. 60068-238 - Environmental testing - Part 2 - 38-Test Z/AD: Composite temperature/ humidity cyclic test. Switzerland, 1974.

15. Altafim RAC, Woschitz R, Ribeiro C, Muhr M, Silva JFR, Calil Junior $\mathrm{C}$ et al. Prototypes of polymer-impregnated reforested wood crossarms subjected to partial discharge tests. In: Proceedings Electrical Insulation Conference and Electrical Manufacturing Expo, 2005, Indianapolis. Indianapolis, 2005. v. 1, p. 225-228.

16. Almeida AEFS and Ferreira OP. Poliuretana Derivada de Óleos Vegetais Exposta ao Intemperismo Artificial. Polímeros. 2006; 16(3):252-256. http://dx.doi.org/10.1590/ S0104-14282006000300017

17. American Society for Testing and Materials - ASTM. D570: Standard Test Method for Water Absorption of Plastics. ASTM; 2010.

18. Cho K-H and Kim Y. Elastic modulus measurement of multilayer metallic thin films. Journal of Material Research. 1999; 14(5):1996-2001. http://dx.doi.org/10.1557/ JMR.1999.0269

19. US Forest Service Research Note. FPL-059 Bending Strength and Stiffness of Plywood. Forest Products Laboratory; 1974. p. 9.

20. Dang Z-M, Yuan J-K, Zha J-W, Zhou T, Li S-T and Hu G-H. Fundamentals, process and applications of highpermittivity polymer-matrix composites. Progress in Material Science. 2012; 57:660-723. http://dx.doi.org/10.1016/j. pmatsci.2011.08.001

21. Silva DAL, Rocco Lahr FA, Faria OB and Chahud E. Influence of wood moisture content on modulus of elasticity on compression parallel. Materials Research. 2012; 15(2):300304. http://dx.doi.org/10.1590/S1516-14392012005000025

22. Gerhard CC. Effect of moisture content and temperature on the mechanical properties of Wood: an analysis of immediate effects. Wood and Fiber. 1982; 14(1):4-36. 